\section{INFORMACIÓN SOBRE LA DEFENSA: DESCONCIERTO Y FALTA DE COSTUMBRE}

\author{
Miguel Ángel Aguilar \\ Secretario General de la Asociación de Periodistas Europeos
}

\begin{abstract}
A fast paced review that follows the transformation of the perception of military and defence affairs from the end of the civil war and the dictatorship to 1977, and then on to 2007, the 30th anniversary of the creation of the Ministry of Defence. It specifically addresses the changes in the attention devoted by the media to these matters starting when the Armed Forces were part of the threat to democracy, as their mission was to prevent it, to the moment they became an instrument of national sovereignty and a fundamental support of Spain's foreign policy.
\end{abstract}

KEY WORDS: Armed Forces; National Defence; francoism; repression; democracy; Constitution; coup d'etat; terrorism; loyalties; transition; concession of military bases to USA; Atlantic Alliance; media; journalists; military service; professional recruits; international missions; culture of Defence.

Este número monográfico de la Revista Arbor que el lector tiene en sus manos está dedicado a "La Cultura de la Defensa Nacional en España" y las líneas que siguen figuran dentro de un apartado que se titula "La información sobre la Defensa Nacional en los medios de comunicación". Entiendo que la solicitud recibida se circunscribe a nuestro país y que interesa un análisis referido al tiempo presente, que sólo será inteligible si esclarecemos de dónde trae causa "La información sobre la Defensa Nacional en los medios de comunicación".

Por eso, aunque sea al galope tendido, debemos repasar el período político anterior, es decir, al franquismo, que a estos efectos consideraremos iniciado el 1 de abril de 1939 y concluido el 28 de diciembre de 1978 con la aprobación en referéndum de la Constitución. El transcurso de más de cuarenta años en silla de pista me ha permitido observar

\section{MEDIA COVERAGE OF DEFENCE: CONFUSION AND LACK OF HABIT}

RESUMEN: RESUMEN: Una rápida revisión, paso a paso, que sigue a la transformación de la percepción de los asuntos militares y relativos a la defensa desde el final de la guerra civil y desde la dictadura hasta 1977 y posteriormente hasta el año 2007, cuando se celebra el 30 aniversario de la creación del Ministerio de Defensa. Específicamente estudia los cambios operados en la atención que los medios de comunicación dedican a estos asuntos y que se inicia en un momento en que las Fuerzas Armadas eran una parte de la amenaza contra la democracia ya que su misión era impedir ésta hasta el momento en que se convierten en un instrumento de la soberanía nacional y un apoyo fundamental a la política de extranjería española de asuntos exteriores españoles.

PALABRAS CLAVE: Fuerzas Armadas; defensa nacional; franquismo; represión; democracia; Constitución; golpe de Estado; terrorismo; lealtad; transición; concesión de bases militares a los Estados Unidos; Alianza Atlántica; medios de comunicación; periodistas; servicio militar; soldados profesionales; misiones internacionales; cultura de la defensa.

cómo ha evolucionado la atención informativa prestada por los medios de comunicación a las cuestiones de la Defensa Nacional, por las que siempre hemos mantenido el mayor interés.

La fecha del 1 de abril de 1939 es la del último parte de guerra sellado por el Estado Mayor del Cuartel General del Generalísimo, cuya versión manuscrita rezaba así: "En el día de hoy, cautivo y desarmado el Ejército Rojo, han alcanzado las tropas nacionales sus últimos objetivos militares. La guerra ha terminado. El Generalísimo Franco. Burgos 1. abril 1939". En principio, sorprende que la mención a los derrotados se haga en los términos de "Ejército Rojo", así con mayúsculas en el vocablo Ejército y en el vocablo Rojo, mientras que el vencedor se reserva para si mismo la más humilde denominación de "tropas nacionales" y lo hace empleando la minúscula para la inicial de cada una de esas palabras. 
También es chocante la construcción gramatical que aparece muy forzada con el uso inadecuado del hipérbaton que invierte la secuencia habitual de sujeto, verbo y predicado. Cuánto más claro hubiera sido escribir con normalidad anteponiendo el sujeto de forma que se hubiera leído que "las tropas nacionales han alcanzado sus últimos objetivos militares". En su lugar se ha preferido una redacción enrevesada que comienza por el verbo -"han alcanzado"- sigue por el sujeto -"las tropas nacionales"- y concluye por el predicado -"los últimos objetivos militares".

Además de atender a estas cuestiones ortográficas referentes al uso de mayúsculas y minúsculas y de cuestionar el inexplicable recurso al hipérbaton que hemos señalado más arriba, conviene fijarse enseguida en la expresión de "Ejército Rojo", elegida como denominación específica para el enemigo derrotado. Porque el "Ejército Rojo", más allá de su fuerte connotación alegórica, carecía de una realidad tangible. Si se hubiera querido llamar a las cosas por su nombre en ese último parte de guerra se hubiera adjudicado la derrota al "Ejército de la República" o a sus residuos finales, que operaban bajo la denominación de "Ejército del Centro". La historia deja constancia de que quien se rindió en Breda fue Mauricio de Nassau y no el inexistente Ejército de Lutero y que el vencido en Waterloo fue Napoleón y no los nunca reclutados Ejércitos de Rousseau o de Voltaire y los enciclopedistas.

Del mismo modo que la madrugada del 8 de mayo de 1945 en el Cuartel General de Eisenhower fue el Jefe del Estado Mayor alemán general Jodl quien firmó la rendición de la Wermacht, sin mención alguna al "Ejército Nazi", que nunca existió como tal, y así sucesivamente. Pero aquí a la altura del 39 en la ribera del río Arlanzón, los acampados en Burgos, parecian mantenerse "impasible el ademán" adictos el lema joseantoniano de que a los pueblos los mueven los poetas. Otra cosa es que enseguida se comprobara cómo a la poesía quedaba superpuesto el prestigio del terror, invocando las exigencias del guión. En todo caso, el prestigio del terror era un elemento psicológico favorecedor para inocular dosis convenientes de docilidad adicional. Claro que la expresión "Ejército Rojo" puede también ser un intento de presentar la del $1 .^{\circ}$ de abril como una victoria obtenida sobre el Comunismo Soviético. De este modo el Generalísimo se encumbraba a sí mismo como vencedor de Trotsky y Stalin.
En la hipótesis más benévola podría pensarse que el último parte de guerra que aquí venimos comentando era una derivación del antiguo precepto de las Ordenanzas según el cual "la consideración y aun la honra del enemigo vencido son compatibles con la dureza de la guerra y están dentro de la mejor tradición española". En esa línea está también la disposición de que a nadie ha de cegar la victoria; que en ella se extremará la disciplina y que con el enemigo vencido se respetarán los derechos y las leyes y usos de la guerra. Pero como enseguida se vio, de eso nada. Del lema con el que Winston Churchill encabezaba sus memorias de guerra -"En la derrota, altivez; en la guerra, resolución; en la victoria, magnanimidad; en la paz, buena voluntad"fue imposible encontrar tampoco rastro alguno a partir de aquella primavera de 1939 y de las siguientes que volvieron sin atender el pronóstico reidor que fijaron las estrofas del "Cara al sol". Ni magnanimidad en la victoria, ni buena voluntad en la paz, que sólo llegaria 39 años después con la Constitución reconciliadora de 1978.

Instalado el régimen del 18 de julio, la cultura de la Defensa Nacional en España fue una cultura de acentos bélicos, dispuesta a mantener la lucha permanente de la España verdadera, recuperada en la cruzada contra la Antiespaña. Una Antiespaña integrada por la horda marxista o dicho en otros términos por cuantos pasaban a considerarse insertos en la conspiración judeo-masónico-bolchevique que había estado a punto de hundir el ser histórico del país. La victoria obtenida contra el frente popular daba nacimiento a un nuevo sistema, el del nacional catolicismo, que se proponía sobre el papel llevar a cabo la revolución pendiente, de carácter nacional sindicalista, proclamada por la Falange. Volvíamos a las órdenes militares de la Edad Media y el buen español debía ser mitad monje, mitad soldado. España pasaba a ser el primer país que había derrotado al comunismo internacional y que por méritos propios se situaba en la vanguardia mundial. Íbamos por rutas imperiales caminando hacia Dios.

Primaba la idea del enemigo interior al que era necesario purgar de sus culpas en los paredones mientras se mantenían cientos de miles de los vencidos en los campos de concentración y en las prisiones para escarmiento general. Los militares de carrera estaban situados en el primer rango de la escala social y los méritos a computar eran sobre todo los méritos de guerra. España era un país ocupado por sus propios ejércitos, que sumaban más de setecien- 
tos mil efectivos sin desmovilizar en atención también a las circunstancias internacionales con la Segunda Guerra Mundial a las puertas de casa. Las simpatías del régimen se orientaban hacia el Eje de Alemania e Italia cuya ayuda en armas y hombres había sido decisiva para la victoria de abril de 1939. Pudo ser necesaria ante los aliados la declaración de "no beligerancia' pero las afinidades eran imborrables y el envío de la División Azul al frente de Rusia constituyó una prueba más.

La derrota de Alemania e Italia dejaba al régimen de Franco en el desamparo internacional con las Naciones Unidas reclamando la retirada de embajadores de Madrid. Aparecian dos grandes categorias de países, los vencedores y los vencidos para los que se habilitaron también ayudas que les permitieran recuperarse de los desastres de la guerra. La España de Franco quedaba en una especie de limbo singular creado para los enemigos residuales aún pendientes de ser derrotados. Ese limbo era un lugar de privaciones al que nunca llegaron por ejemplo los fondos del Plan Marshall. Pocos años después cundió la escisión entre los aliados que dio paso a la "guerra fría". Para las nuevas alineaciones que esa situación originó la geografía peninsular adquirió un nuevo valor enseguida muy apreciado por el Pentágono. Así llegaron a propiciarse a la altura del año 1953 los acuerdos hispano-norteamericanos sobre las Bases Militares, que dieron oxígeno vital a un sistema político desfalleciente. Porque el franquismo, banderas al viento, invocaba pasadas grandezas mientras la población seguía con cartillas de racionamiento.

En España cuestiones como la de los acuerdos de Defensa con Washington, estaban reservadas al general Franco y a su entorno más inmediato de El Pardo. En momento alguno fueron objeto de debate público ni tampoco se sometieron a aquellas Cortes orgánicas, mera caja de resonancia a base procuradores de familia, municipio y sindicatos y de consejeros nacionales del Movimiento de libre designación. Los ciudadanos permanecían encerrados en el corralito de la minoría de edad política, estaban entrenados en el escarmiento y tenían bien aprendido que incurrir en la discrepancia significaba deslizarse por la pendiente de la desafección, un lugar en extremo desapacible, donde se oía el llanto y el crujir de dientes.

El servicio militar tenía carácter obligatorio para los varones, de forma que los jóvenes de cualquier extracción social quedaban durante ese período bajo la férula y la disciplina castrense. Eran 12 meses de oportunidad para infundir cultura de la Defensa Nacional en grandes dosis pero apenas dejaban un rastro de "historias de la puta mili" como escribió Antonio Muñoz Molina. Suponían una gravosa interrupción de los estudios o de la primera inserción profesional y tras la instrucción, el destino a las unidades se vivía como el lugar donde no se hacía nada pero más deprisa. Iba amainando la influencia del Frente de Juventudes y los tecnócratas ayudaban a salir de la autarquía hacia la inserción de España en el sistema de las inversiones y el comercio internacional. Entraba el turismo para broncearse al sol de nuestras playas pero traía también costumbres licenciosas, descendía el cumplimiento del precepto dominical, empezaban a reclamarse derechos y libertades públicas, se entronizaba la moda del pacifismo y encabalgada sobre ella la objeción de conciencia al servicio militar. Era una especie de enmienda a la totalidad a los principios del Movimiento que resultaba de muy difícil encaje y empezaba a tener consecuencias penales para sus protagonistas más tenaces, que acababan en las prisiones de las que salian para volver a entrar cuando de nuevo se negaban a incorporarse al servicio obligatorio tras otro llamamiento. En aquellos años, un general, Manuel Díez Alegría, propuso buscar una solución legal al problema y pagó semejante osadía con el ostracismo.

El franquismo entendía que los asuntos de la Defensa quedaban reducidos a los altos mandos de las Fuerzas Armadas. Este peculiar entendimiento se reflejó paradójicamente al terminar la guerra en la supresión del ministerio de Defensa, cuyas atribuciones se fraccionaron para pasar en parte al departamento de la Presidencia del Gobierno y dividirse entre los tres ministerios reaparecidos del Ejército, de Marina y del Aire. Era todo un despropósito que multiplicaba estructuras y gastos en momentos de penuria presupuestaria. Pero obedecía al reflejo de abierta desconfianza de Franco en sus colegas de armas. Había recibido de ellos el poder en un aeródromo rural de Salamanca $y$, sabedor de que sólo los uniformados podian reclamárselo, quiso fomentar la desunión y el enfrentamiento entre sus filas para ahuyentar el peligro de que se le volvieran en contra. En cuanto a la creación del Alto Estado Mayor, con misiones de coordinación de los tres ministerios militares pero sin rango superior al ministerial, se trataba de un imposible ajeno a la más elemental lógica administrativa según la cual sólo se 
puede ser coordinador desde un escalón más elevado al de los coordinados.

La liturgia del régimen consagraba dos días al año a la exaltación de sus valores: el de la Pascua Militar -festividad fijada el 6 de enero desde su institución por el rey Carlos III cuando la recuperación de Menorca- que Franco celebraba en el Palacio entonces Ilamado de Oriente, y el del desfile de la Victoria, cuya fecha oscilaba alrededor del 30 de mayo que el santoral dedica a Fernando III el Santo. Dos jornadas de grandilocuencia en los discursos del Salón del Trono y de agasajo en las tribunas del paseo de la Castellana de Madrid, a cambio de otras 363 de silencio ritual, salvo la comparecencia uniformada de las autoridades militares junto a las civiles y religiosas en cuantas ceremonias de otra índole la requiriesen. En los medios de comunicación ésa era también la pauta. Páginas y páginas en los periódicos de esos días, retransmisión en directo de los actos por Radio Nacional a la que conectaban todas las otras emisoras y también por TVE, que tenía unidad de audiencia porque era la única en funcionamiento. Ni matices ni objeciones, todo eran resplandores y cánticos a la excelencia de los nuestros y a sus glorias sin eclipses.

En suma, como escribió Julio Cerón, "cuando murió Franco el desconcierto fue grande, no había costumbre". Los militares profesionales se sentían a la muerte de Franco el 20 de noviembre de 1976 depositarios de las garantías para la continuidad de su régimen a tenor de la promesa que el Generalísimo había hecho años antes en el cerro de Garabitas a sus incondicionales, formulada en términos de que "todo quedará atado y bien atado bajo la guardia fiel de nuestro Ejército". Claro que en aquel testamento, leído con Iloriqueos por el presidente del Gobierno Carlos Arias Navarro la mañana del 20-N, también Franco se dirigía a los militares para decirles "os pido que rodeéis al futuro Rey de España, don Juan Carlos de Borbón, del mismo afecto y lealtad que a mí me habéis brindado y le prestéis en todo momento el mismo apoyo y colaboración que de vosotros he tenido". El margen para las interpretaciones era suficiente para que cundiera el desasosiego y se hiciera aún más difícil el cambio de lealtades de Franco al Rey Juan Carlos, quien desde el primer momento puso sus deberes con el pueblo español por encima de los juramentos a las Ilamadas Leyes Fundamentales y a los Principios del Movimiento, proclamados como permanentes e inaltera- bles pero improrrogables más allá de la muerte de quien las había dictado.

Tras la dimisión de Carlos Arias Navarro -un desastre sin paliativos-, Adolfo Suárez, Ilegaba en junio de 1976 a la presidencia del Gobierno elegido por el Rey de entre una terna donde había sido incrustado por Torcuato Fernández Miranda, presidente del Consejo del Reino. Su designación fue saludada como un inmenso error por quienes se maliciaban que los orígenes falangistas de Suárez prejuzgaban que intentaría sostener el improrrogable Movimiento. El organigrama del Gobierno venía a ser el mismo con el mantenimiento de la innovación de Arias Navarro, que se había dotado de una Vicepresidencia primera para Asuntos de Defensa y Seguridad en la que continuaba el teniente general Fernando de Santiago y Díaz de Mendívil. Eso, sin perjuicio de las tres carteras militares de Ejército, Marina y Aire, cuyos titulares seguían en ejercicio.

El nuevo presidente hizo oídos sordos a esos presagios y se aplicó a desmontar con esmero y delicadeza - de la ley a la ley, pasando por la ley- la herencia recibida y a buscar la homologación con el entorno político europeo. Por eso planteó la Ley de la Reforma Política, cuya votación suponía el harakiri de la clase política del régimen y abría la posibilidad de convocar las primeras elecciones generales libres. Para que fueran inobjetables se consideraba necesario ese mínimo de igualdad de oportunidades que entrañaba la legalización de los contendientes, a la que se procedió en dos tiempos, primero, los sindicatos y después, los partidos políticos, incluido el Comunista.

La legalización de los sindicatos arrastró en septiembre de 1976 la dimisión como vicepresidente primero para Asuntos de la Defensa del teniente general Fernando de Santiago y Díaz de Mendivil, que fue sustituido por el también teniente general Manuel Gutiérrez Mellado. El 9 de abril de 1977, festividad del Sábado Santo, la legalización del Partido Comunista de España fue seguida por la dimisión fulminante del ministro de Marina, almirante Gabriel Pita da Veiga, sin que se encontrara ningún almirante en activo dispuesto a relevarle, de forma que hubo de recurrirse a la reserva para designar a Pascual Pery Junquera. Entre los altos mandos del Ejército cundió la impresión de haber sido traicionados y el Consejo Superior lanzó una nota incandescente de advertencia en el límite de la insubordinación, que dejaba al Gobierno contra las cuerdas. En ese momento los directores 
de los diarios de la ciudad de Madrid respondieron con un editorial conjunto, que puso a los militares en su sitio y les recordó que debian permanecer a las órdenes del Gobierno, cuyas competencias para proceder a la legalización del PCE respaldaban plenamente.

Eran momentos que ahora codificamos como de idilica transición pero que en realidad registraban fuertes turbulencias. Apenas quedaba espacio para la reflexión política en torno a la Defensa Nacional. Una materia que durante décadas había venido siendo coto cerrado, reservado sólo a los altos mandos militares con acceso vedado a la ciudadanía, que llevaba décadas excluida como menor de edad. Se imponía la terminología del "ruido de sables" y, bajo esos efectos especiales, los partidos recién llegados a la legalidad pasaban a entender que las Fuerzas Armadas más que parte vital de la Defensa eran parte decisiva de la Amenaza Nacional. Una Amenaza inminente que pendía sobre nuestras libertades y derechos entonces en fase inaugural.

Así que, en medio de las convulsiones referidas, un sector relevante de los militares profesionales derivó hacia el golpismo, concebido como el camino más corto para asegurar la cuarteada perennidad del régimen que fenecía, y se instalaron en el antagonismo hacia cuantos propugnaban la reforma o la ruptura, vocablos bajo los que se etiquetaba un conglomerado del que formaban parte también los medios de comunicación social. Los militares profesionales se sentían escrutados por una prensa que consideraban hostil. Su reacción era encausar ante los tribunales castrenses a los periodistas incómodos por injurias y calumnias. A la reciproca, los periodistas tenían la propensión de atribuir a todos los militares de carrera una abierta intencionalidad golpista. Todo esto ambientado por el terrorismo etarra que tenía predilección por los uniformados y multiplicaba sus atentados con víctimas mortales, que pasaron de la veintena en los años 74, 75, 76 y 77, a cerca de 80 en el 78, más de 100 en el 79 y más de 120 en el 80.

Los envites que se jugaban en el tapete de los símbolos tenían especial significación. Por ejemplo, el desfile de la Victoria carecía de sentido que continuara con ese nombre cuando íbamos hacia la paz reconciliadora. Porque la Victoria que hasta entonces se conmemoraba no era la de Lepanto contra el Turco, ni la de las Navas de Tolosa contra los almorávides ni la de Bailén contra el invasor Napoleón. La Victoria celebrada, era la de unos españoles que, ayudados por la morisma y los contingentes italianos y alemanes, habian vencido el 1 de abril del 39 bajo el caudillaje de Franco, a otros españoles encuadrados en el ejército popular de la República, que contaron en algunos momentos con el apoyo de las Brigadas Internacionales. Y si la conmemoración era ocasión de orgullo para los primeros, también significaba humillación para los segundos.

En estos asuntos de las Fuerzas Armadas y de la Defensa se imponía emprender la construcción de un nuevo orgullo en el que todos los españoles pudieran coincidir, sin que la exaltación de unos compatriotas significara denigración para otros. Por eso, a partir de 1977 el desfile hubo de cambiar su denominación y pasar a apellidarse "de las Fuerzas Armadas". Parecería una cuestión sencilla, de mero nominalismo intrascendente, pero fue un ejercicio muy complicado para evitar que se encendieran esas susceptibilidades que en el ámbito simbólico suelen llevar una carga explosiva adosada.

La invocación de la objeción de conciencia por parte de quienes la ley denominaba "mozos", o sea de los jóvenes reclutables, se difundía cada vez más en las postrimerías del franquismo. Los Ayuntamientos desobedecian las normas de reclutamiento y se situaban al borde de la insumisión. Por eso, tuvo plena lógica que en la Constitución de 1978 se encomendara el reconocimiento de la objeción de conciencia al servicio militar obligatorio a una ley específica que habría de aprobarse. Una ley que establecía también la alternativa de otro servicio, el de la prestación social sustitutoria, para quienes se declararan objetores. Enseguida, el nuevo sistema empezaba a hacer aguas. Crecía de manera desmesurada la bolsa de objetores pendientes de destino, surgía la objeción a la prestación social sustitutoria y el incumplimiento de las tareas legales encomendadas a los ayuntamientos para el alistamiento, en una u otra de las modalidades del servicio, tomaba caracteres cada vez más graves en especial en determinadas áreas del País Vasco.

Adolfo Suárez creaba el ministerio de Defensa en julio de 1977 y se lo encomendaba al vicepresidente primero, teniente general Manuel Gutiérrez Mellado. Al mismo tiempo se suprimían los ministerios del Ejército, Marina y Aire, siempre encomendados a tenientes generales y almirantes en activo. En el nuevo departamento cundía la idea de que en algún momento la cartera podría pasar a manos de un civil y los altos oficiales adoptaron como medida preven- 
tiva una interesante distinción entre "la cadena de mando militar" y "la rama político-administrativa". El "mando" quedaba reservado a los militares de carrera y los políticos cuando llegaran quedarian confinados en la "rama".

Gutiérrez Mellado buscaba promover el interés de los medios de comunicación por los asuntos de la Defensa, más allá de la retahíla de incidentes que se sucedian. En esos días fui llamado por el ministro a su despacho y de esa reunión salió la convocatoria de una serie de cursos que se desarrollaron en el CESEDEN para instruir en estas materias a los periodistas que designaran los medios. El objetivo era formar expertos que pudieran valorar las noticias de esta área y darles un seguimiento profesional. De modo que, por ejemplo, las nuevas dotaciones de material para cada uno de los ejércitos fueran evaluadas con criterio y la opinión se hiciera una composición de lugar sobre lo que representaban para la operatividad de las fuerzas que respaldaban el ejercicio de la soberanía nacional y daban fortaleza a la política exterior. En adelante, en las redacciones habría alguien interesado en hacer espacio a esos asuntos y con capacidad técnica y criterio para juzgar sobre su relevancia.

El primer civil nombrado para Defensa fue Agustín Rodríguez Sahagún, que anduvo trashumante por los Cuarteles Generales, como invitado por los respectivos Jefes de Estado Mayor. Esa fue también la situación de Alberto Oliart, que asumió esa cartera tras el 23-F en el gobierno de Leopoldo Calvo Sotelo. Recordemos que bajo su presidencia se sustanció el proceso a los implicados en el 23-F, cuya vista en el Instituto Geográfico del Ejército proporcionó momentos de alta tensión que se reflejaron en los medios de comunicación con singular fuerza cada vez que los periodistas pasaron a ser considerados indeseables por los encausados. La falta de gallardía que mostraron, su pretensión de excusarse unos en otros, sin que ninguno diera un paso al frente, como hiciera el general Sanjurjo para asumir en exclusiva la plena responsabilidad ante el tribunal que le juzgaba por la intentona del 10 de agosto de 1932, causó una impresión penosa en la opinión pública. Los enconos se activaron hasta niveles como aquellos del Cucut, que antagonizaron a militares y periodistas.

A falta de información sobre la Defensa Nacional todo se reducia a noticias sobre incidentes al hilo de estas rela- ciones tormentosas. El ministro Oliart intentaba interesar a los medios a propósito de los nuevos aviones de caza que habian de sustituir a los viejos Sabre del Ejército del Aire y convocaba sesiones para presentar un estudio comparado sobre las ventajas e inconvenientes de los dos modelos que habían quedado en la lista corta: el F-16 de la General Dynamics y el F-18 de la Loched, ambos de procedencia norteamericana, pero nunca supimos por qué ningún fabricante europeo había sido seleccionado. Escaldado por el 23-F, Calvo Sotelo decidió en un Consejo de Ministros celebrado el 20 de agosto de 1981 solicitar el ingreso de España en la OTAN conforme había anticipado en su programa de investidura. Hubiera sido un asunto de gran relevancia para debatir pero se prefirió poner a las demás fuerzas políticas ante los hechos consumados, con la consecuencia de la ruptura del consenso en un momento en que los socialistas presentían su próximo triunfo electoral y querían demostrar que todo podía hacerse con ellos pero que sin ellos todo se haría imposible. La decisión fue respaldada por el Congreso de los Diputados pero las consecuencias vinieron después.

Hubo que esperar al primer Gobierno de Felipe González para que su ministro de Defensa, Narcís Serra, fuera dotado de una sede propia en el edificio que había sido hasta entonces Ministerio de Cultura y antes de Información y Turismo. La victoria socialista por mayoría absoluta supuso una prueba de resistencia y proporcionó algunas imágenes imborrables. Los militares habían sido educados en el franquismo más ortodoxo para ser la vanguardia en la lucha contra la mencionada conspiración internacional que sitiaba al régimen, de la que por supuesto consideraban parte al PSOE. Pero allí estaban en formación todos los mandos para saludarle después de que en el patio de armas del Cuartel General del Ejército se le rindieran por las tropas los honores de ordenanza.

Las cuestiones de la Defensa Nacional seguian sin recibir tratamiento informativo alguno. En cuanto a las fuerzas democráticas que habían vertebrado la oposición a la dictadura venían de aplicarse en exclusiva a la reivindicación de los derechos humanos y de las libertades cívicas y estaban ayunas de reflexión y pensamiento sobre los asuntos de la política internacional y de la Defensa. Siguiendo anteriores inercias las resoluciones de los primeros congresos de los partidos que accedian a la legalidad proclamaban la solidaridad con las justas casas de los pueblos oprimidos 
y se inclinaban por la adhesión al movimiento de los no alineados con el que anduvimos flirteando.

La incorporación a la Alianza Atlántica que había sido una exigencia subyacente en las negociaciones de adhesión a la Comunidad Económica Europea, era vista como una manera de uncirnos a la militarización del pensamiento político, por decirlo con palabras de Fernando Morán, que sería ministro de Asuntos Exteriores tras la victoria electoral socialista de 1982. Y los acuerdos de Defensa con Estados Unidos sobre las bases militares se consideraban un lastre a nuestra soberanía porque además, mientras en otros países europeos los norteamericanos habían sido los liberadores del yugo nazi-fascista, en España su llegada tuvo el efecto de apoyar al régimen franquista en dificultades y darle la circulación internacional de la que carecía. Todo convergía así para distorsionar las simpatías y antipatías internacionales de los españoles en abierto contraste con las detectadas en los sondeos de los países de nuestro entorno.

La democracia naciente venía extremando sus consideraciones para desactivar los recelos. Recibía unas Fuerzas Armadas ideologizadas, en estado de penuria en cuanto a sus dotaciones y entrenamiento y con una macrocefalia que multiplicaba sus costes y su ineficiencia. Los militares de carrera habian de compensar la escasez de sus emolumentos con el recurso al pluriempleo y los altos mandos recibian en premio diferentes gabelas en el Instituto $\mathrm{Na}$ cional de Industria y demás áreas públicas cuando llegaban a la aventurada edad de la reserva. Se mejoró la atención presupuestaria en todos los capítulos y se trazaron programas plurianuales para racionalizar las modernizaciones necesarias en el Ejército de Tierra, en la Armada y en el Ejército del Aire.

Las nuevas dotaciones de material respondian a necesidades detectadas pero también a la hipnosis imparable que despiertan las nuevas tecnologías. La operabilidad de todo el material y de los sistemas de armas a bordo de los vehículos de Tierra, de los buques y de las aeronaves necesitaban servidores con mayores períodos de adiestramiento pero los períodos del servicio militar obligatorio se iban acortando de modo que todo el esfuerzo gastado en preparar a los reclutas se perdía por su rápido licenciamiento. De ahí, y por contagio acelerado al suprimirse la conscripción en los Estados Unidos una vez terminada la guerra de Vietnam, la nueva preferencia entre oficiales, jefes y generales por unas Fuerzas Armadas basadas en la voluntariedad de los profesionales. La nueva escuela de pensamiento hacía abstracción de los efectos colaterales de la recluta profesional, con graves repercusiones en el ámbito de la "Cultura de la Defensa", y sólo hacía hincapié en las ventajas de unos contingentes que se mantendrian en filas al menos durante cuatro años.

El presidente Suárez se mostraba refractario a la Alianza Atlántica y soñaba en el papel que España podría desempeñar fuera de ese esquema. Pero la intentona del 23-F de 1981 confirmó al nuevo presidente Leopoldo Calvo Sotelo la idoneidad de sumarse a la OTAN. Lo hizo un poco por sorpresa y sin obtener el consenso del PSOE que se sentía crecido en vísperas de alcanzar el Gobierno. Por ahí, con una buena dosis de despecho, avanzó la campaña del "OTAN, de entrada no", que tanto éxito reportó a los socialistas para tener que desactivarla después, cuando se instalaron en la Moncloa, a partir de 28 de octubre de 1982. La Alianza, que pasaba a ser piedra de toque de nuestro alineamiento internacional y de nuestra política de Defensa, traía un arrastre polémico que se prorrogaría cuatro años más hasta el referendum sobre la permanencia de nuestro país, que se celebró en febrero de 1986.

Los medios de comunicación respiraban entonces un progresismo más bien primitivo y acompañaban a buen paso los recelos muy poco atlantistas de Suárez. La rápida maniobra de Calvo Sotelo para el ingreso en la OTAN tuvo poco ambiente mediático y luego, en contraste, hubo mucha coincidencia, próxima al entusiasmo por el vértigo, para exigir la convocatoria del referéndum prometido. Aqui cabe situar otro vértice relevante porque, feliz con su embestida, el líder de la entonces Alianza Popular, Manuel Fraga, encaminó a su partido hacia la abstención, sin dejarse influenciar por sus socios internacionales que nunca le perdonaron ese comportamiento y lo excluyeron de sus círculos políticos. Felipe González hubo de desandar el camino de aquellos lemas tan efectistas para la victoria del 82. Imbuido de sus responsabilidades abogó por la permanencia en la Alianza, eso sí, con una retahíla de condiciones sobre la desnuclearización del territorio y la reducción de la presencia militar norteamericana.

Los nuevos acuerdos Hispano-norteamericanos, que negoció el gobierno de Felipe González convirtieron las ba- 
ses militares navales y aéreas en únicamente españolas y acuñaron los términos de Instalaciones de Apoyo (IDAS), que se facilitaban a las Fuerzas de los Estados Unidos, y de Autorizaciones de Uso (ADUS), que debían solicitar en cada caso. Ya había cambiado la canción y además la otra parte contratante se empleó a fondo moviendo sus peones españoles, que tenía contratados desde hacía tiempo como mercenarios. La vileza de las campañas emprendidas contra el negociador español, el embajador Máximo Cajal, para debilitar su posición merece pasar a las antologías de la infamia. La redacción final de los acuerdos supuso el levantamiento de las hipotecas que pesaban sobre nuestra soberanía nacional desde 1956 y el final de nuestra minoría de edad en el ámbito internacional.

Bajo los gobiernos socialistas España fue tomando crecientes compromisos en misiones de desarme, de mantenimiento de la paz o de interposición. Primero en algunos países de América Central y luego en los Balcanes, en unos casos bajo bandera de Naciones Unidas y en otros, de la Alianza Atlántica. Así empezábamos a asumir las cargas que nos correspondian conforme a nuestra posición en la tabla e interiorizábamos la idea de una Defensa Nacional avanzada, a distancia, preventiva. En 1996 la victoria a los puntos del Partido Popular situaba a José María Aznar en la presidencia del Gobierno. Ningún partido de los que contendían en esa convocatoria con ambiciones de poder a escala nacional había incorporado a su programa electoral la supresión del servicio militar obligatorio pero bastó una sugerencia de Convergencia i Unió para que se hiciera la luz y la eliminación del servicio militar se incluyera en el programa para la investidura parlamentaria de Aznar.

Así que, primero, fue la improvisación sobrevenida y, enseguida, la precipitación. Porque sin planificación alguna el sistema que iba a abandonarse se derrumbó de modo súbito sin atender ningún plazo. Nadie quería ser el último pringado con la mili. La idea de una dosificación progresiva de militares profesionales para relevar los contingentes en disminución procedentes del servicio obligatorio se hizo impracticable. Se abrieron las convocatorias para tropa y marinería profesional tanto a varones como a mujeres pero resultaron poco atractivas en un momento de disminución del paro. Enseguida, fue necesario rebajar las exigencias de formación, cociente intelectual y condiciones físicas y al mismo tiempo abrir la posibilidad a candidatos de otras nacionalidades. El artículo 30 de la Constitución dice que "los españoles tienen el derecho y el deber de defender a España" pero la supresión del servicio militar se hizo sin reemplazar esa obligación por ninguna otra.

Haciendo de la necesidad virtud el Ministro de Defensa, Eduardo Serra, descubría el papel de ariete para la inclusión social de los inmigrantes que podian desempeñar las Fuerzas Armadas. Pero semejante propósito suponía atribuir a nuestros ejércitos misiones excéntricas, como en otro momento anterior pudo ser la alfabetización o la formación profesional. Además, la invocación de ese papel produce en todos nosotros ruido de cristalería cerebral porque desconcierta que el "ardor guerrero" de la primera estrofa del Himno de Infantería sea el que vayan a sentir henchidos de patriotismo español precisamente los extranjeros.

Sucede que la deriva hacia las Fuerzas Armadas profesionales se ha producido en medio de una coyuntura económica expansiva cuando el paro sigue descendiendo. De manera que la oferta de plazas en las filas de los ejércitos sólo atrae a los que están en la base de la pirámide ocupacional expuestos a las mayores vulnerabilidades y necesitados de encontrar alguna vía contundente para obtener la nacionalidad que todo lo soluciona o al menos, como premio, los papeles que les permitan su contratación legal. Frente a estas observaciones enseguida aparecen algunos funcionalistas para traernos ejemplos de acoplamiento de los extranjeros en las fuerzas armadas de distintos países y mencionan a los Gurkas con larga tradición en el Reino Unido o a los Regulares que tanto rendimiento le dieron a Franco en la guerra civil dispuestos como buenos mahometanos a defender la civilización cristiana según reconocía en sus versos el conde de Foxá.

El caso es que, cuando por primera vez, las Fuerzas Armadas se encontraban cumpliendo misiones en países exóticos donde alcanzaban como aquí un magnífico reconocimiento social, se hacian notar graves dificultades para alcanzar los efectivos deseados en número y en calidad. $\mathrm{Ni}$ el incremento de las pagas y de las primas de enganche, ni las mejoras en los alojamientos, ni la reforma del régimen de vida de las unidades fue suficiente para paliar el déficit de reclutamiento. Podrá decirse que la vida muelle a la que muchos se apuntan contradice los requerimientos del oficio castrense pero ahí está la disponibilidad de tantos jóvenes que se enrolan en las más difíciles situaciones 
sin atender para nada a sus intereses personales cuando consideran que está en juego una causa que vale la pena. De manera que se impone un análisis más severo de la desmotivación para el oficio de las armas en la versión de nuestros días. Una versión que viene gozando por lo general en nuestro país de muy buena prensa.

El último ministro que esbozó un programa para impulsar la Cultura de Defensa creo recordar que fue Eduardo Serra, pero todas sus propuestas fueron protestadas al presentarse en la Comisión de Defensa del Congreso de los Diputados. Todos sus planes escolares se consideraron poco menos que intoxicadores y excitaron la indignación de los nacionalistas. Tampoco prosperó la idea de baremar el servicio prestado en filas como mérito en concursos para la función pública o en cuerpos como los de las policías autonómicas o municipales, o en los de auxiliares de los ministerios o de las Comunidades Autónomas.

En los casi treinta años transcurridos desde la entrada en vigor de nuestra Constitución los cambios en el ámbito de la Defensa Nacional han tenido extraordinaria relevancia conforme se ha ido reflejando las páginas precedentes. Para empezar las expresiones Defensa o Defensa Nacional eran todavía excéntricas al discurso político en el inicio del período democrático. Se prefería hablar de uno de sus instrumentos, el militar. La referencia básica era el Ejército en el que se subsumía tanto la Armada como el Ejército del Aire. Es el recurso a la sinécdoque, una de las variantes de la metonimia, que consiste en tomar la parte por el todo. Algo así como lo que sucede cuando se menciona a la prensa para designar al conjunto de los medios de comunicación, donde se incluye también la radio y la televisión.

El Ejército tenía sobre la Armada y la Aviación una abrumadora superioridad numérica pero se encontraba en grave inferioridad comparativa respecto a su modernización conceptual, de dotaciones, de adiestramiento y de relaciones operativas con sus homólogos de otros países. Recordemos que veníamos de la Ley Orgánica del Estado de 1966, a tenor de la cual las Fuerzas Armadas estaban constituidas por los Ejércitos de Tierra, Mar y Aire y Fuerzas de Orden Público. Obsérvese en contraste la opción adoptada en el artículo $8 .^{\circ}$ de la Constitución de 1978, según el cual las Fuerzas Armadas están constituidas en exclusiva por el Ejército de Tierra, la Armada y el Ejército del Aire. Es una definición restringida que, como explica el profesor Manuel Ballbé, en su libro Orden público y militarismo en la España constitucional, estaba cargada de consecuencias. Significaba una ruptura porque hasta ese momento -en medio de tantas discontinuidades del régimen jurídico político español como se suceden a partir de la Constitución de Cádiz de 1812 de la sucesión de monarquías, destronamientos, revoluciones, restauraciones, dictablandas y dictaduras- podía identificarse un elemento invariable: el de la entrega a los mandos militares del control del orden público, es decir, de las libertades públicas.

Así se explica, por ejemplo, que el 18 de julio fueran los generales, al frente de las distintas divisiones -nueva denominación de las antiguas Capitanías adoptada por la Segunda República-, quienes proclamaran el estado de guerra en el territorio de su jurisdicción, invocando las atribuciones legales que tenían conferidas. Además en el franquismo victorioso de la posguerra civil se encomendaba a los tribunales militares la represión de las actividades subversivas, en las que se inscribian todas las disidencias del régimen. También se entregaba a la jurisdicción castrense a cualquier manifestante que se enfrentara a los agentes de las Fuerzas de Orden Público, conforme a la lógica derivada de la condición militar de los mismos y habida cuenta del carácter prevalente del fuero castrense cuando entraba en conflicto con el ordinario. Balvé subraya que es en la Constitución de 1978 donde por primera vez se desmilitariza el orden público y por tanto la administración de las libertades públicas queda liberada del control de los uniformados. Estas rápidas pinceladas pueden dar idea de la fricción permanente que veníamos arrastrando entre los partidos y sindicatos de la oposición democrática y las instituciones militares y también de los recelos que, en consecuencia, se fueron instalando en las percepciones públicas.

En resumen, durante décadas la Defensa Nacional estaba fuera del discurso político. Prevalecía el reduccionismo de limitar las referencias al Ejército y a los militares, la mayoría de las veces a propósito del protagonismo que habian desempeñado como represores de cuantas actividades desafiaban al régimen franquista. Sólo después de la Constitución hubo una redefinición de los papeles asignados a las fuerzas armadas y empezaron a manejarse los conceptos más elementales en materia de Defensa. Con mucha lentitud estas realidades fueron permeando hacia los medios de comunicación social. Pero hasta fechas muy 
recientes la carencia de centros de estudio y pensamiento sobre asuntos Internacionales y de Defensa y la falta de interés en las Universidades ha dificultado la creación de una dinámica de debate y de una ideación de alternativas a contrastar. Recordemos, por ejemplo, las polémicas surgidas en torno a la necesidad de dotarnos de campos como el de Cabañeros, declarado parque natural por el presidente de Castilla-La Mancha, José Bono, ignorante de que culminaría su vida política como ministro de Defensa.

Debe reconocerse que la situación ha ido evolucionando sin grandes aceleraciones pero de modo progresivamente favorable. Así al Instituto Español de Estudios Estratégicos (IEEE), incardinado en el Centro Superior de Estudios de la Defensa Nacional (CESEDEN), se le han ido sumando el INCIPE, el CERI, el CIDOB, el Instituto Manuel Gutiérrez Mellado de Paz Y Seguridad, la fundación FRIDE o el Real Instituto Elcano. En cuanto al plano de la activación de los medios de comunicación y de sus profesionales, es obligado mencionar una iniciativa casi solitaria de la Asociación de Periodistas Europeos con sus Seminarios sobre la Defensa en Europa, iniciados en Toledo en 1982 que el año 2007 alcanzó su XIX edición. Expertos políticos, diplomáticos, militares, universitarios y periodistas procedentes de los países de la UE y de otros de la Alianza Atlántica, en especial de los Estados Unidos, debaten allí las cuestiones de Defensa más relevantes en cada momento. También han surgido publicaciones especializadas como Política Exterior, Dossier Vanguardia o la edición en castellano de Foreing Policy.

Los asuntos de la Defensa Nacional gozaron del consenso para llevar a cabo las reformas legales desarrolladas por iniciativa de los diversos gobiernos de UCD, del PSOE y del PP hasta el 2004. Los titulares de la cartera de Defensa -Agustín Rodríguez Sahagún, Alberto Oliart, Narcís Serra, Julián García Vargas, Gustavo Suárez Pertierra, Eduardo Serra y Federico Trillo- cultivaron los encuentros con los portavoces de Defensa de los grupos parlamentarios para anticiparles iniciativas, evitarles sorpresas y atemperar reacciones. En sus relaciones con la Comisión de Defensa del Congreso por lo general practicaron un sistema peculiar que alternaba la sequía de la incomparecencia prolongada con la inundación de sesiones de ocho o diez horas seguidas, que abrumaban a los diputados y les dejaban sin capacidad de absorber el alud de información aportada en forma de voluminosos dossiers que los ujieres depositaban en los escaños mientras el ministro seguía en el uso de la palabra.

El consenso fue también norma para la participación de contingentes de las Fuerzas Armadas en las Operaciones de Mantenimiento de la Paz (OMPs) a partir de la de 1988 en Angola (UNAVEM I) hasta que el presidente José María Aznar optó por el unilateralismo. Pensó que podría sustituir al Reino Unido como aliado privilegiado de los Estados Unidos en Europa y sacar a España del rincón de la historia. El procedimiento fue poner los pies sobre la mesa en una reunión del G-8 y hacer de figurante en la reunión de las Azores donde se dio el ultimátum previo a la guerra de Iraq. Otra cosa es que después de salir en la foto junto al presidente norteamericano George W. Bush y el premier británico Tony Blair, la contribución de España al acontecimiento bélico fuera el envío de un barco hospital con instrucciones de demorarse lo suficiente para llegar al puerto iraquí de destino una vez que hubiera concluido la invasión.

En todo caso, Aznar batalló en el Consejo de Seguridad, del que España formaba entonces parte como miembro no permanente, en pro de una resolución que autorizara la invasión de Iraq dando por buenas las armas de destrucción masiva que nunca existieron. Su actitud rompió todos los consensos y suscitó las mayores protestas populares que se recuerdan y la oposición generalizada de los medios de comunicación. El daño resultante de esta división enconada de los españoles en la calle y en los escaños del parlamento a propósito de los asuntos de política internacional y de Defensa ha venido a instalarse desde entonces como una penosa constante que disminuye el peso de nuestro país en la escena mundial. Al pasar a la oposición tras la derrota del 14 de marzo de 2004 el PP ensayó la ruptura de todos los consensos también en el plano de la Defensa pese a los intentos en sentido contrario primero del ministro José Bono y después de José Antonio Alonso que tomó su relevo.

Todavía con Aznar, el incidente del deshabitado islote de Perejil vecino a Ceuta, donde acamparon unos gendarmes marroquíes desalojados enseguida mediante una operación militar -"al alba y con fuerte viento de levante"-, que quiso presentarse como una reedición de Iwo Jima, marcó un momento de alta tensión patriótica explotada con descaro por la prensa que más amarillea. Para su desactivación la 
ministra de Exteriores Ana Palacio requirió los servicios arbitrales del secretario de Estado norteamericano, Colin Powell, con el que quedamos en deuda. En cuanto al presidente José Luis Rodríguez Zapatero fue notable su estreno con la orden de retirada inmediata de las fuerzas españolas enviadas a las misiones de reconstrucción y ayuda humanitaria a Iraq, que indignó más a la oposición del PP que a Washington. La ley de las compensaciones aconsejó después que España se sumara a las operaciones de Afganistán bajo mando OTAN con el envío de un con- tingente militar. Una decisión que el PP trató de presentar como incoherente con la salida de Iraq.

En los medios de comunicación social todas estas vicisitudes se reflejaron sobre todo en términos del peculiar ping-pong entre el PP y el PSOE, de declaraciones y contradeclaraciones, sin brindar apenas espacio al análisis de las razones subyacentes a las decisiones adoptadas que hubieran podido aportar esclarecimientos. Como reza el título de este trabajo: desconcierto y falta de costumbre.

Recibido: 14 de enero de 2008

Aceptado: 17 de marzo de 2008 